\title{
Carboxyterminal Peptide Fragments of the Beta Subunit Are Urinary Products of the Metabolism of Desialylated Human Choriogonadotropin
}

\author{
Sania Amr, Cesar Rosa, Steven Birken, Robert Canfield, and Bruce Nisula \\ Developmental Endocrinology Branch, National Institute of Child Health and Human Development, National Institutes of Health, \\ Bethesda, Maryland 20205; and Department of Medicine, Columbia University College of Physicians and Surgeons, New York 10032
}

\begin{abstract}
Previous investigations of patients with gestational trophoblastic neoplasia have shown that their urines often contain carboxyterminal peptide (CTP) fragments of the choriogonadotropin (hCG) $\beta$-subunit as well as forms of hCG deficient in sialic acid. In order to determine whether $\beta$-CTP fragments are among the urinary products of the peripheral degradation of desialylated hCG (as-hCG), using a continuous infusion technique, we gave highly purified as-hCG to humans. Six healthy subjects were given a loading dose of $0.8 \mathrm{mg}$ of as-hCG followed by an infusion of the same preparation. An overall mean infusion rate of $62.9 \mu \mathrm{g} / \mathrm{min}$ was maintained for $6 \mathrm{~h}$, and the mean serum concentration of as-hCG achieved during the infusion was $72.1 \mathrm{ng} / \mathrm{ml}$. In all six subjects, $\beta$-CTP fragments were the predominant immunoreactive forms of as-hCG in urine obtained during the infusion. In contrast, the urine of subjects infused with hCG has been shown to contain hCG itself, but nil $\beta$-CTP fragments or as-hCG. After the as-hCG infusion was stopped, the excretion of the $\beta$-CTP fragments in urine declined rapidly. There were no $\beta$-CTP fragments detectable in sera obtained during the infusion or in sera incubated with as-hCG at $37^{\circ} \mathrm{C}$. After incubation with as-hCG for $4 \mathrm{~h}$, the urine of normal subjects contained small amounts of $\beta$ CTP fragments; however, the apparent proteolytic activity was too low to account for either the quantity of $\beta$-CTP fragments produced during the infusion or the extremely low levels of ashCG in the urine. These data demonstrate the existence in humans of a peripheral metabolic pathway that cleaves $\beta$-CTP fragments from as-hCG and allows their excretion in urine. Thus, the frequent presence of $\boldsymbol{\beta}$-CTP fragments in the urines of patients with gestational trophoblastic neoplasia can be accounted for in part by the metabolism of the forms of hCG that bear an altered carbohydrate structure, which are prevalent in this disease.
\end{abstract}

\section{Introduction}

Several investigations have given evidence for a disparity between the forms of human choriogonadotropin (hCG) ${ }^{1}$ secreted by the normal placenta and those secreted by neoplastic

Address reprint requests to Dr. Amr, Bldg. 10, Rm 10N262, National Institutes of Health, Bethesda, MD 20205.

Received for publication 11 September 1984 and in revised form 31 December 1984.

1. Abbreviations used in this paper: as-, asialo-; CTP, carboxyterminal peptide; hCG, human choriogonadotropin; MCR, metabolic clearance rate; $R C R$, renal clearance rate; RIA, radioimmunoassay.

The Journal of Clinical Investigation, Inc.

Volume 76, July 1985, 350-356 trophoblast (1-7). The abnormal forms of hCG and their metabolites are of clinical interest as potential molecular markers of the malignant transformation of the trophoblast. Recently, we have reported identification of two novel types of hCG-related molecules, which occur commonly in the urines of patients with gestational trophoblastic neoplasia but rarely in the urines of pregnant women (8). The first type consists of fragments of the hCG $\beta$-subunit that lack the conformational antigenic determinant required for cross-reactivity in the $\beta$-core radioimmunoassay (RIA) (SB6 antiserum), but retain the $\beta$-carboxyterminal peptide (CTP) antigenic determinant. The second type consists of desialylated forms of hCG that cross-react in a RIA that requires galactose-terminated $O$-serine carbohydrate in the $\beta$-CTP region $(8,9)$. Since neither desialylated forms of hCG nor $\beta$-CTP fragments were found in the urine of normal subjects after infusion of highly purified hCG (8-10), we hypothesized that CTP fragments of the hCG $\beta$-subunit could be products of the metabolism of abnormal forms of hCG, such as those deficient in sialic acid. We tested this hypothesis by analyzing the urines of healthy subjects who were given an infusion of asialo-hCG (as-hCG). We found that $\beta$-CTP fragments are indeed urinary products of the peripheral metabolism of as-hCG.

\section{Methods}

Preparation of desialylated $h C G$. Highly purified hCG (batch CR121) was desialylated and characterized biologically and physicochemically as previously reported (11). The desialylated preparation was processed for human administration by Millipore filtration (Millipore Corp., Bedford, MA).

Subjects. Six healthy volunteers, three men and three women, aged 21-67 yr, were given an infusion of as-hCG after a loading dose of 0.8 $\mathrm{mg}$ injected intravenously. A continuous infusion of $350 \mathrm{ml}$ of $0.9 \%$ $\mathrm{NaCl}$, containing as-hCG and $2 \mathrm{ml}$ of $25 \%$ human serum albumin, was maintained at a flow rate of $50 \mathrm{ml} / \mathrm{h}$ for $6 \mathrm{~h}$. An aliquot of the infusate given to each subject was stored at $-20^{\circ} \mathrm{C}$. A blood sample was withdrawn from the contralateral arm each hour during the infusion. Urine specimens were collected every $2 \mathrm{~h}$ during the $6 \mathrm{~h}$ of infusion and 6,12, and $24 \mathrm{~h}$ thereafter. Sera and aliquots of the urine collections were stored at $-20^{\circ} \mathrm{C}$.

Radioimmunoassays (RIAs). RIAs were carried out employing antisera directed toward the hCG $\beta$-core (SB6) and hCG $\beta$-CTP (R525) antigenic determinants; these RIAs have been previously characterized $(12,13)$. The same as-hCG preparation as given to the subjects was used as the reference preparation and the radioligand in the RIAs. Iodination of as-hCG with [ ${ }^{125}$ I] iodide was performed by using the chloramine $T$ method, and the specific activity of the ${ }^{125} \mathrm{I}-$ as-hCG was $50-75 \mu \mathrm{Ci} / \mu \mathrm{g}$. Normal male serum and urine were used to compensate for nonspecific effects in the RIAs when sera or urines were assayed directly. RIA potencies were expressed in terms of mass of the highly purified as-hCG preparation. The least detectable doses per tube were $\sim 0.2$ and $1.0 \mathrm{ng}$ in the $\beta$-core and $\beta$-CTP RIA, respectively.

Acetone concentrates of the urine specimens were prepared as follows: the $\mathrm{pH}$ of the urine specimen was adjusted to 5.5 with acetic 
acid, and acetone was added 2:1, vol/vol. The mixture was incubated overnight at $4^{\circ} \mathrm{C}$, and the precipitate was lyophilized and reconstituted with distilled water.

Gel filtration. A Sephadex G-100 column $(1.6 \times 86 \mathrm{~cm})$ was used with an upward flow rate of $13 \mathrm{ml} / \mathrm{h}$. Each sample was loaded in a 2$\mathrm{ml}$ volume and eluted with phosphate buffer saline, $\mathrm{pH}$ 7.4. Radiolabeled as-hCG and hCG $\alpha$-subunit were used as internal markers with each column run. Aliquots of each $2.0-\mathrm{ml}$ fraction were assayed in duplicate in both hCG $\beta$-core and hCG $\beta$-CTP RIAs. The aliquot volume varied from 200 to $600 \mu$. The least detectable amount in each fraction was determined from the fraction volume and the least detectable dose per tube.

Generation of $\beta-C T P$ fragments in urine. To assess the extent to which $\beta$-CTP fragments are produced from as-hCG in urine itself, we performed the following experiment: as-hCG was incubated at various concentrations for $4 \mathrm{~h}$ at $37^{\circ} \mathrm{C}$ in urines obtained from the volunteers. The samples were assayed in both the $\beta$-core and the $\beta$-CTP RIAs to determine the total concentration of immunoreactivity. Aliquots of the urines were chromatographed on the Sephadex G-100 column to characterize the immunoreactive moieties present. Also, aliquots of the urines enriched with as-hCG were concentrated by the acetone procedure to determine the recovery of as-hCG with this method.

Calculations. The metabolic clearance rate (MCR) and renal clearance rate (RCR) were calculated as previously described (14), using formulas available elsewhere (15). Body surface area was estimated from height and weight according to the formula of DuBois and DuBois (16). Statistical analysis was performed as previously reported (17).

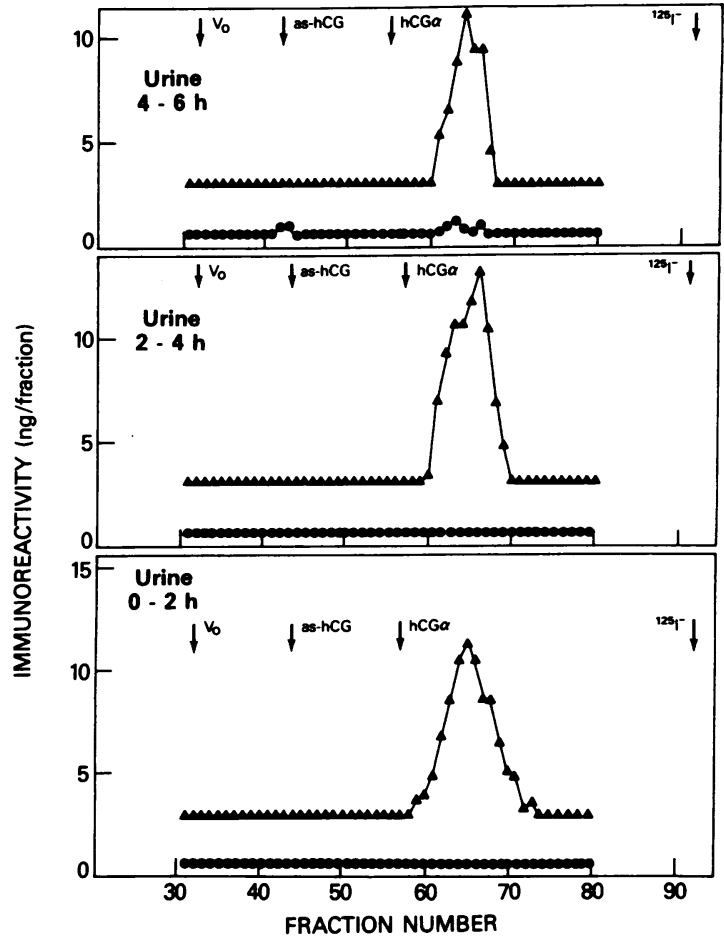

Figure 1. Sephadex G-100 gel filtration of urine specimens collected from subject 4 between 4 and $6 \mathrm{~h}$ (top), from subject 1 between 2 and $4 \mathrm{~h}$ (middle), and from subject 6 between 0 and $2 \mathrm{~h}$ (bottom) during the infusion of as-hCG. A 2-ml aliquot of untreated urine was filtered and the eluted fractions were assayed for $\beta$-core immunoreactivity in using the SB6 antiserum and for $\beta$-CTP immunoreactivity in using the R525 antiserum. Fractions obtained from filtration of preinfusion urine contained no detectable $\beta$-core or $\beta$-CTP immunoreactivity. $\Delta$, hCG $\beta$-CTP; $\bullet$, hCG $\beta$-core.

\section{Results}

Gel filtration of urine specimens. To determine whether the $\beta$ CTP fragments occur as urinary products of the metabolism of as-hCG, urine specimens obtained from the subjects at three different times during the infusion were chromatographed on the Sephadex G-100 column. All of the urine specimens contained $\beta$-CTP fragments, i.e., $\beta$-CTP immunoreactive material of an apparent molecular size smaller than that of the $\alpha$-subunit marker (Figs. 1-3). Indeed, in all the urines obtained during the infusion, $\beta$-CTP fragments were the predominant immunoreactive forms that were found (Figs. 1-4).

Interestingly, neither as-hCG nor fragments that exhibit $\beta$-core immunoreactivity were detected in 3 of the subjects' urines (Fig. 1). In the other subjects' urines, the total levels of immunoreactivity were so low that acetone concentrates were prepared before chromatography to determine whether $\beta$-CTP fragments or $\beta$-core fragments or as-hCG were present. Sephadex G-100 gel filtration of the urine concentrates demonstrated that $\beta$-CTP fragments were indeed present in these urines as well (Figs. 2 and 3). The elution profiles obtained with samples from subject 3 were very similar to those depicted in Fig. 2 (data not shown).

In addition to the $\beta$-CTP fragments, $\beta$-core immunoreactive material of molecular size smaller than that of hCG $\alpha$ (i.e., $\beta$-core fragment material) was present in most of the urine concentrates (Figs. 2 and 3). Notably absent, or at best barely detectable, in five of the six subjects' urines was immunoreactivity in the region where the as-hCG marker eluted (Figs. 1 and 2). Only one subject excreted substantial amounts of forms similar in molecular size to as-hCG during the 6-h

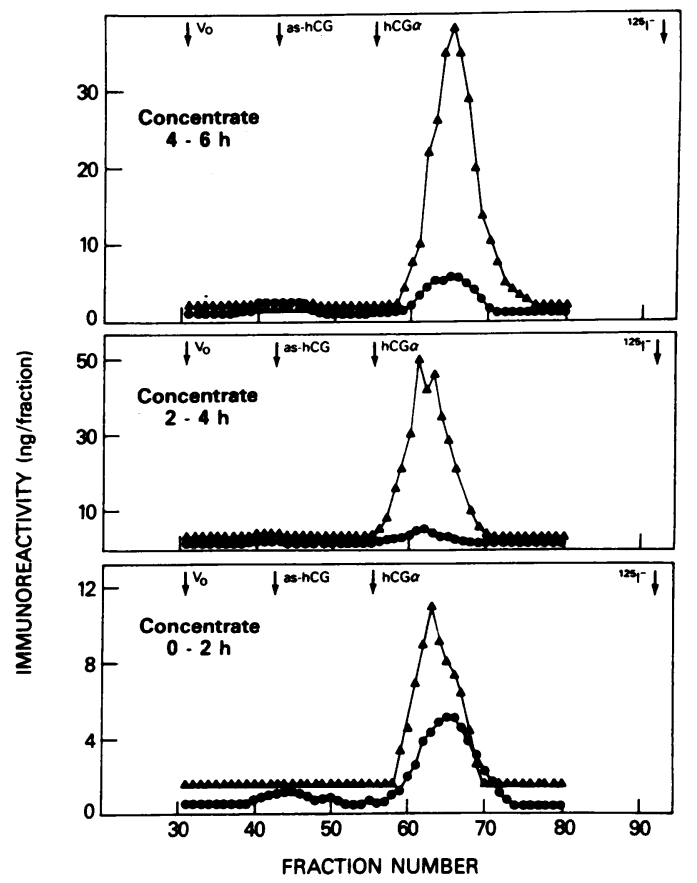

Figure 2. Sephadex G-100 gel filtration of acetone concentrates of urine specimens obtained from subject 2 at different times during the infusion of as-hCG. A 2-ml aliquot of urine concentrate was filtered and the eluted fractions were assayed as described in the legend of Fig. 1. $₫$, hCG $\beta$-CTP; $\bullet$, hCG $\beta$-core. 


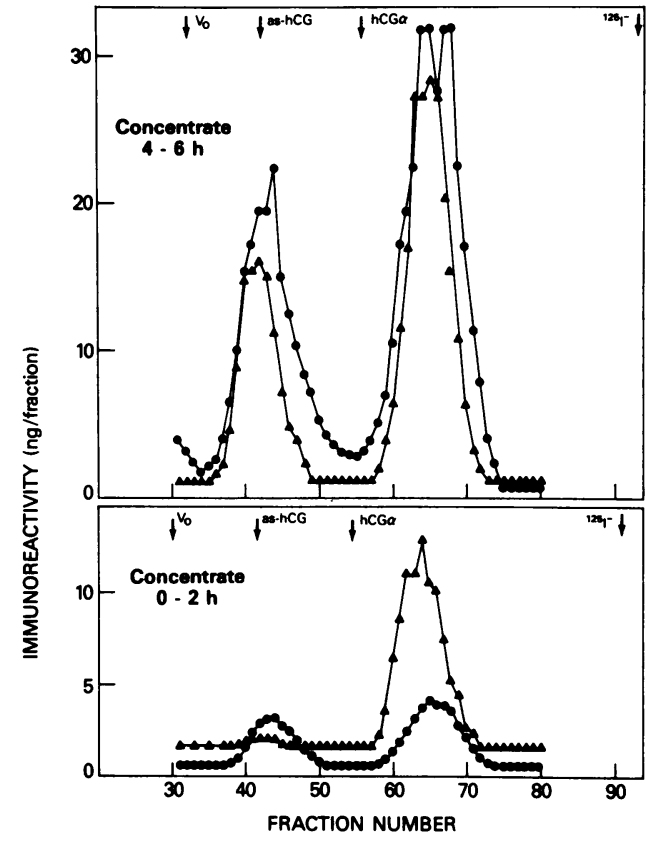

Figure 3. Sephadex G-100 gel filtration of acetone concentrates of urine specimens obtained from subject 5 at different times during the infusion of as-hCG. The samples were processed as described in the legend of Fig. 1. 4 , hCG $\beta$-CTP; •, hCG $\beta$-core.

infusion time (Fig. 3). This individual stood out in another respect-his urine output was the highest $(245 \mathrm{ml} / \mathrm{h})$ of the group $(145 \pm 54 \mathrm{ml} / \mathrm{h}$, mean $\pm \mathrm{SD})$.

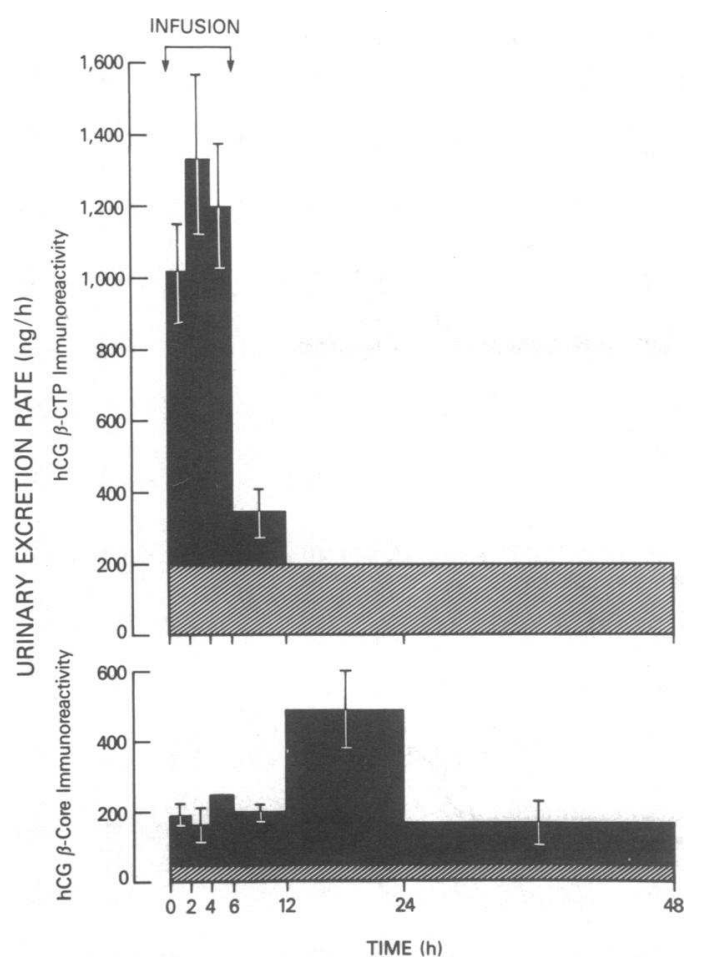

Figure 4. Urinary excretion rates (mean \pm SEM) of total $\beta$-CTP (top) and total $\beta$-core (bottom) immunoreactivities in the urines of subjects given a 6-h infusion of as-hCG after a $0.8-\mathrm{mg}$ bolus injection. The shaded areas indicate the limits of detection.
Kinetics of excretion of urinary $\beta-C T P$ fragments. To explore the timing of the excretion of $\beta$-CTP in relationship to the as-hCG infusion, the concentrations of both $\beta$-CTP and $\beta$-core immunoreactivities were measured in urines collected during and after the infusion. In that the urine volumes varied between the subjects at different times, the excretion rates in nanograms per hour of both immunoreactivities were determined for each subject. Excretion of $\beta$-CTP immunoreactivity in the urine occurred as early as the first $2 \mathrm{~h}$ of the as-hCG infusion (upper panel, Fig. 4). The average excretion rate remained fairly constant $(\sim 1,200 \mathrm{ng} / \mathrm{h})$ during the infusion period (Fig. 4, upper panel); and on a molar basis, it appeared to exceed the excretion rate of $\beta$-core immunoreactivity by a factor of about 6 (compare upper and lower panels, Fig. 4). This disparity between the urinary excretion of $\beta$-CTP and $\beta$-core immunoreactivities, added to their elution patterns on the Sephadex G-100 column (Figs. 1-3), shows that on the average, $>80 \%$ of the $\beta$-CTP immunoreactivity in urines obtained during the infusion consisted of $\beta$-CTP fragments. At the end of the infusion the excretion rate of $\beta$-CTP immunoreactivity rapidly decreased, becoming undetectable in urines collected $6 \mathrm{~h}$ after stopping the infusion (Fig. 4, upper panel). In contrast, the excretion rate of $\beta$-core immunoreactivity peaked in the urines collected 6-18 $\mathrm{h}$ after stopping the infusion (Fig. 4, lower panel). This delayed pattern of excretion of $\beta$-core immunoreactivity is reminiscent of results obtained with the hCG $\beta$-subunit (18).

Metabolic and renal clearance rates of as-hCG. Continuous infusion of as-hCG after the $0.8-\mathrm{mg}$ bolus produced serum levels of as-hCG that remained quite stable from the 1st to the 6 th $h$ of infusion. The mean as-hCG level in the sera was similar among the six subjects (Table I); they averaged 72.1 $\mathrm{ng} / \mathrm{ml}$ with an overall mean infusion rate of $62.9 \mu \mathrm{g} / \mathrm{min}$. The mean MCR of as-hCG was $494.9 \pm 96.6 \mathrm{ml} / \mathrm{min} \cdot \mathrm{m}^{2}$ (mean $\pm \mathrm{SD}$ ). Using a single injection technique to estimate the MCR of as-hCG, we obtained a value of $349 \pm 96 \mathrm{ml} / \mathrm{min} \cdot \mathrm{m}^{2}$, previously (11). Both of these values for the MCR of as-hCG are several orders of magnitude greater than that for hCG $\left(1.88 \pm 0.08 \mathrm{ml} / \mathrm{min} \cdot \mathrm{m}^{2}(14)\right.$.

Based on the total amount of $\beta$-CTP immunoreactivity excreted during the $6-\mathrm{h}$ infusion and the amount of $\beta$-CTP immunoreactivity eluting in the position of as-hCG (Figs. 13 ), we estimated that the RCR of the as-hCG itself was less than $0.615 \mathrm{ml} / \mathrm{h} \cdot \mathrm{m}^{2}$. In contrast, the renal clearance rate of intact hCG is $24 \mathrm{ml} / \mathrm{h} \cdot \mathrm{m}^{2}(14)$ or at least 39 -fold greater than that of as-hCG. Thus, the renal processing of as-hCG is radically different from that of native hCG.

The mean total amounts of $\beta$-CTP and $\beta$-core immunoreactivities excreted over the $48 \mathrm{~h}$ were 9.2 and $12.6 \mu \mathrm{g}$, respectively. This is equivalent to $\sim 0.05 \%$ of the total amount of as-hCG immunoreactivity infused into each subject (22.9 $\mathrm{mg}$ ) over the $6-\mathrm{h}$ period. These data demonstrate that renal excretion of as-hCG, $\beta$-core fragments, and $\beta$-CTP fragments with immunoreactivity actually contributes little to the overall metabolic disposal, and therefore the MCR, of the as-hCG molecule. The renal excretion of native hCG, on the other hand, accounts for $21.7 \%$ of its disposal (14).

Gel filtration of serum. To gain insight into the mechanism of generation of $\beta$-CTP fragments in vivo, we assessed whether these fragments were detectable in serum obtained during the infusion. Sera obtained at $6 \mathrm{~h}$ of infusion were chromatographed on the Sephadex G-100 column. No serum sample contained 
Table I. MCR of as-hCG in Human Subjects as Determined by a Continuous Infusion Technique

\begin{tabular}{|c|c|c|c|c|c|c|c|}
\hline Subject & Sex & Weight & Height & Body surface & Infusion rate* & Serum as-hCG & MCR \\
\hline & & $k g$ & $\mathrm{~cm}$ & $m^{2}$ & $\mu g / \min$ & $n g / m l$ & $\mathrm{ml} / \mathrm{min} \cdot \mathrm{m}^{2}$ \\
\hline 1 & $\mathbf{F}$ & 64.8 & 162 & 1.69 & 59.8 & $75.2 \pm 21.3 \ddagger$ & 476.9 \\
\hline 2 & $\mathbf{F}$ & 59.1 & 157 & 1.59 & 66.4 & $72.7 \pm 4.6$ & 574.4 \\
\hline 3 & $\mathbf{F}$ & 59.6 & 166 & 1.66 & 72.2 & $65.0 \pm 21.2$ & 668.7 \\
\hline 4 & $\mathbf{M}$ & 71.5 & 179 & 1.89 & 55.6 & $74.6 \pm 9.9$ & 394.3 \\
\hline 5 & $\mathbf{M}$ & 70.4 & 172 & 1.82 & 55.8 & $71.4 \pm 12.9$ & 421.7 \\
\hline 6 & $\mathbf{M}$ & 84.0 & 187 & 2.09 & 68.1 & $75.1 \pm 21.3$ & 433.8 \\
\hline
\end{tabular}

* A loading dose of $0.8 \mathrm{mg}$ of as-hCG was injected intravenously at the onset. $¥$ Mean \pm SD of $\beta$-core immunoreactivity levels in sera obtained during the 6-h infusion.

detectable $\beta$-CTP fragments (Fig. 5 and 6 ). In three of the subjects, the serum $\beta$-core and $\beta$-CTP immunoreactivities eluted in the same position as the ${ }^{125} \mathrm{I}$-as-hCG (Fig. 5). In two other subjects, the major peak of $\beta$-core immunoreactivity also eluted in the position of ${ }^{125} \mathrm{I}$-as-hCG; and there was a minor peak of $\beta$-core immunoreactivity in the region of small molecular size (Fig. 6), but there were no $\beta$-CTP fragments evident. Based on the area under the eluted peaks, these $\beta$-core fragments constituted $\sim 18 \%$ of the total $\beta$-core immunoreactivity in the eluate. The $\beta$-core fragments appeared in the elution profiles of the $6 \mathrm{~h}$ serum specimens of only two of the five subjects. None was apparent in any of five samples obtained at $5 \mathrm{~h}$ or at $1 \mathrm{~h}$ (data not shown).

Generation of $\beta-C T P$ fragments in urine. To investigate the contribution of the urine itself to the production of $\beta$-CTP fragments by proteolytic cleavage of the as-hCG molecule, we

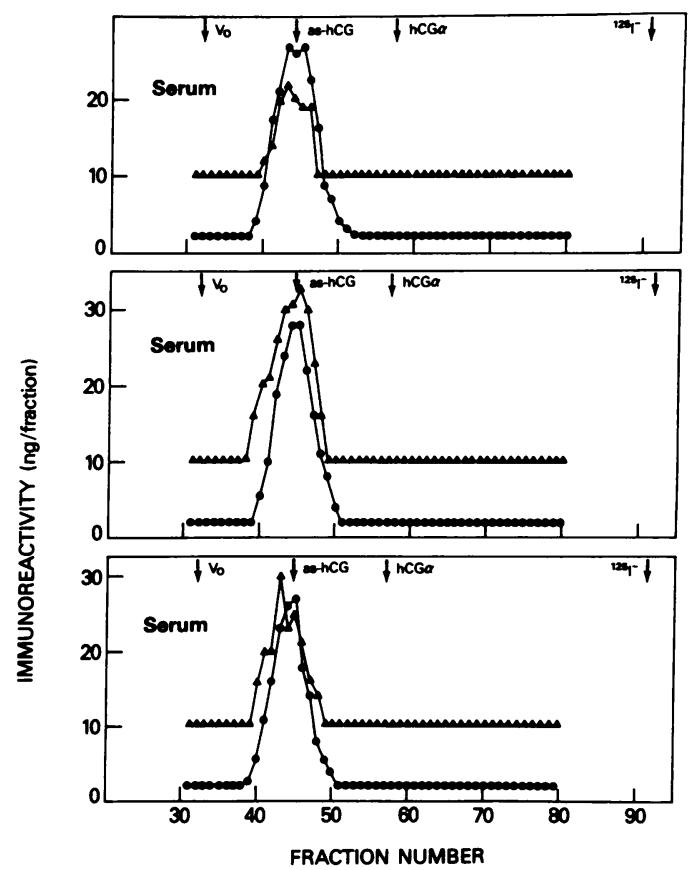

Figure 5. Sephadex G-100 gel filtration of sera obtained from subject 3 (top), subject 1 (middle), and subject 4 (bottom) after $6 \mathrm{~h}$ of infusion of as-hCG. A 2-ml aliquot of each sample was filtered and the eluted fractions were assayed as described in the legend of Fig. 1. $\Delta$, hCG $\beta$-CTP; •, hCG $\beta$-core. incubated different concentrations of as-hCG with normal urines at $37^{\circ} \mathrm{C}$ for $4 \mathrm{~h}$. After storage under the same conditions as the urines obtained during the study, the samples were assayed by using the $\beta$-core and the $\beta$-CTP RIAs. If incubated at a concentration of $1 \mu \mathrm{g} / \mathrm{ml}$ as-hCG, the as-hCG immunoreactivities recovered were $0.89 \pm 0.06 \mu \mathrm{g} / \mathrm{ml}$ and $0.83 \pm 0.04$ $\mu \mathrm{g} / \mathrm{ml}$ (mean $\pm \mathrm{SD}$ of six determinations) in $\beta$-core and $\beta$-CTP RIAs, respectively; and if incubated at a concentration of 0.66 $\mu \mathrm{g} / \mathrm{ml}$, the amounts recovered were $0.62 \pm 0.02 \mu \mathrm{g} / \mathrm{ml}$ and $0.59 \pm 0.03 \mu \mathrm{g} / \mathrm{ml}$, respectively. The urinary immunoreactivity eluted from the Sephadex G-100 column mainly in the position of the ${ }^{125} \mathrm{I}$-as-hCG marker. There was $\beta$-CTP immunoreactivity clearly detectable in the position of the $\beta$-CTP fragments (Fig. 7 , upper panel). However, compared to the quantity of $\beta$-CTP fragments evident in the urine during the infusion of as-hCG (Fig. 1), the quantity generated from as-hCG in the urine during processing was quite low.

To estimate the recovery of as-hCG by the acetone concentration procedure, 50,100, and $200 \mu \mathrm{g}$ of as-hCG were added to three urine specimens and the acetone extracts were prepared. The mean recoveries of $\beta$-core and $\beta$-CTP immunoreactivities in the concentrates were 59 and $66 \%$, respectively (Table II). As expected, the elution profile on Sephadex G-100

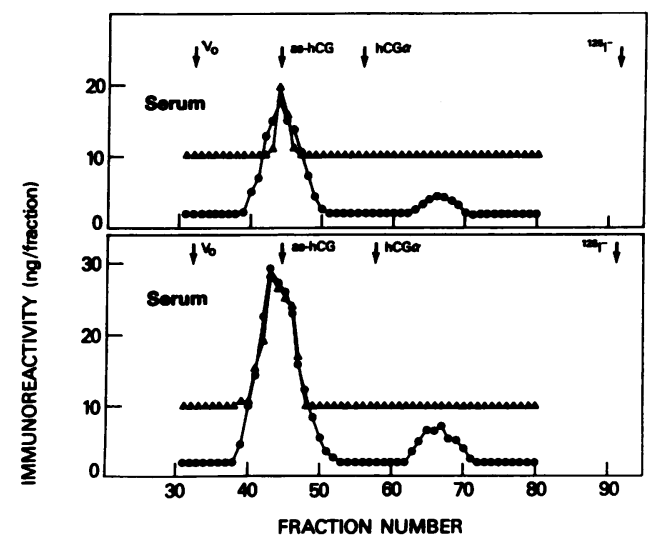

Figure 6. Sephadex G-100 gel filtration of sera obtained from subject 2 (top), and subject 6 (bottom) after $6 \mathrm{~h}$ of infusion of as-hCG. The eluted fractions were assayed as described in the legend of Fig. 1. Fractions obtained from filtration of control sera exhibited no detectable $\beta$-core or $\beta$-CTP immunoreactivity. $₫$, hCG $\beta$-CTP; $\bullet$, hCG $\beta$-core. 


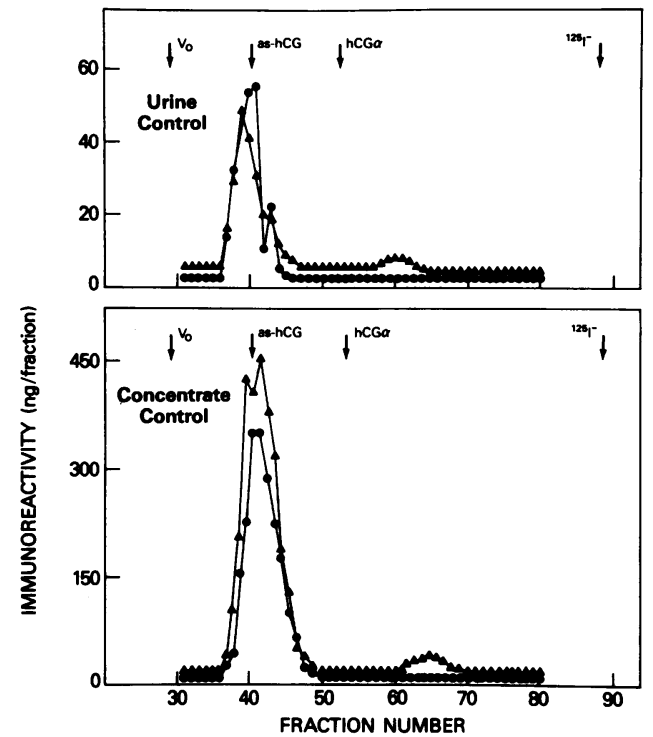

Figure 7. Sephadex G-100 gel filtration of normal urine incubated with as-hCG at $37^{\circ} \mathrm{C}$ for $4 \mathrm{~h}$ (top), and the acetone concentrate of normal urine incubated with as-hCG (bottom). $\Delta$, hCG $\beta$-CTP; $\bullet$, hCG $\beta$-core.

showed the presence of a small amount of $\beta$-CTP fragments in the concentrate (Fig. 7, lower panel).

Although $\beta$-CTP fragments were not detected in the sera, it appeared possible that they could be generated therein and rapidly cleared by the kidney and excreted in the urine. However, the contribution of serum proteolysis to the generation of $\beta$-CTP fragments is nil, as incubation of as-hCG with normal serum at $37^{\circ} \mathrm{C}$ for $3 \mathrm{~h}$ did not generate any detectable $\beta$-CTP fragments (11).

\section{Discussion}

Previously, we reported that hCG $\beta$-CTP fragments were present in the urines of patients with choriocarcinoma but not in those of normal pregnancy (8). In that the $\beta$-CTP fragments were often associated with unusual forms of hCG that were desialylated in the $\beta$-CTP region, we formulated the hypothesis that these fragments could be degradation products of the unusual forms of hCG. Indeed, in the present study, we found evidence for the existence in humans of a peripheral metabolic pathway that cleaves $\beta$-CTP fragments from as-hCG. Healthy subjects that were given an infusion of as-hCG excreted $\beta$ CTP immunoreactive material of molecular size smaller than

Table II. Recovery of the $\beta$-Core and $\beta$-CTP Immunoreactivities of as-hCG from Urine by the Acetone Concentration Procedure

\begin{tabular}{llllll}
\hline & \multicolumn{1}{l}{$\beta$-core } & & & $\beta$-CTP & \\
\cline { 2 - 3 } \cline { 5 - 6 } Sample & Amount & Recovery & & Amount & Recovery \\
\hline & $\mu g$ & $\%$ & $\mu g$ & $\%$ \\
1 & $32.0 \pm 2.8^{*}$ & $64.0 \pm 5.6$ & & $35.4 \pm 1.9$ & $70.8 \pm 3.8$ \\
2 & $57.6 \pm 6.8$ & $57.6 \pm 6.8$ & & $69.2 \pm 4.0$ & $69.2 \pm 4.0$ \\
3 & $115.7 \pm 13.4$ & $57.8 \pm 6.7$ & & $123.6 \pm 17.7$ & $61.8 \pm 8.8$
\end{tabular}

* Mean \pm SD of six determinations of as-hCG immunoreactivity. that of the $\alpha$-subunit. The apparent molecular weight of the $\beta$-CTP fragments, based on the elution position from Sephadex G-100, was between 13,000 and 15,000 . The $\beta$-CTP fragment that we previously characterized in the urine of a patient with choriocarcinoma had an apparent molecular weight of 14,000 and was similar, if not identical, to the desialylated hCG $\beta$ glycopeptide containing residues 115-145 (8). These observations suggest that the frequent presence of $\beta$-CTP fragments in the urines of patients with gestational trophoblastic neoplasia can be accounted for in part by peripheral metabolism of the forms of hCG bearing an altered carbohydrate structure that are prevalent in this disease.

It has been shown that incompletely sialylated forms of hCG are secreted by human choriocarcinoma cell lines in vitro (19). We and others have reported that desialylated forms of hCG occur in the urines of patients with choriocarcinoma $(8,9,20)$. Hence, it was somewhat unexpected in the present study to find that very little of the injected as-hCG was excreted in urine, despite our having given a constant infusion to maintain a substantial blood level over the 6-h period. The apparent difference in excretion of desialylated forms of hCG between choriocarcinoma patients and our subjects infused with as-hCG could be explained by the fact that we used desialylated native hCG in the present study, whereas the extent of sialylation of the abnormal forms of hCG in our patients with choriocarcinoma was not known. The abnormal forms of hCG present among patients with choriocarcinoma may well have contained somewhat more sialic acid than did our preparation; the antiserum that was used to detect the desialylated forms of $h C G$ required desialylation of $h C G$ only on its $\beta$-CTP region for immunoreactivity $(9,21)$ and other regions could have been variably sialylated. Also, that the number of sialic acid residues present on the molecule might variably affect renal excretion seems evident from our observed difference in the renal clearance rates of hCG and as-hCG (24 $\mathrm{ml} / \mathrm{h} \cdot \mathrm{m}^{2}$ vs. $\left.<0.615 \mathrm{ml} / \mathrm{h} \cdot \mathrm{m}^{2}\right)$. Thus, it is plausible that the incompletely sialylated forms of hCG that occur in choriocarcinoma have RCRs intermediate between those of hCG and as-hCG. Another factor of potential relevance is urine volume. The urine output of the subject who excreted the highest levels of as-hCG during the infusion was $\sim 68 \%$ higher than the average output of the other subjects. Another possible explanation is that gestational trophoblastic neoplasia might affect peripheral metabolic mechanisms for hCG and related molecules.

Although our data clearly demonstrate that the urinary $\beta$ CTP fragments are products of as-hCG metabolism, just where the $\beta$-CTP fragments are generated remains unknown. In that desialylation appear to render glycoproteins more susceptible to the action of proteases $(22,23)$, and proteases are ubiquitous, cleavage could occur in serum, urine, or tissues. Incubation of as-hCG with serum at $37^{\circ} \mathrm{C}$ produced no $\beta$-CTP fragments (11). On the other hand, incubation of as-hCG in normal urine at $37^{\circ} \mathrm{C}$ for $4 \mathrm{~h}$ generated $\beta$-CTP fragments, but in too low an amount to account for more than a tiny fraction of the $\beta$-CTP fragments evident in the urines of infused subjects. Also, there was negligible as-hCG in the urines of infused subjects to serve as substrate for this proteolytic process. Furthermore, the fact that the $\beta$-CTP fragments and the $\beta$ core fragments appeared in the urines at different times indicates that the pathways involved in the processing of these two fragments are distinct, and thus, they are not generated 
simply by proteolytic cleavage in the urine. The latter process would be expected to yield the fragments in the same timeframe. Hence, as-hCG processing by urine per se appears not to be responsible for the production of the $\beta$-CTP fragments. Evidently, tissue proteases are involved.

In vitro studies have demonstrated that as-hCG binds to human membrane preparations of liver, kidney, and thyroid tissue (24-26). Both in vitro and in vivo animal data indicate that the liver is the major tissue for the removal of asialoglycoproteins from the circulation (27-30). In humans, however, metabolism of as-hCG within the kidney could be quantitatively more important than it is in animals; the affinity of human kidney membranes for as-hCG has been reported to be nearly the same as that of human hepatic membranes (25). Even though hepatic tissues (or others) theoretically could contribute to the production of the $\beta$-CTP fragments that we detect in urine, several other observations are consistent with proteolysis within the kidney being a major factor: $(a)$ Studies in rats indicate that catabolism of glycoprotein hormones occurs in the kidney $(31,32)$, and as-hCG is no exception in this regard (Lefort, G. P., J. M. Stolk, and B. C. Nisula, unpublished observation) (33). (b) The RCR of as-hCG is $<2.56 \%$ that of intact hCG, whereas presumably the amount of as-hCG filtered at the glomerulus is, if anything, greater than the amount of hCG, in that as-hCG is the smaller molecule. Thus, the renal tubular epithelium appears to be processing more filtered ashCG than filtered hCG. (c) Urine alone was capable of cleaving $\beta$-CTP fragments from as-hCG, albeit relatively inefficiently. The presumed protease may well be renal in origin in that serum exhibited no such activity. $(d)$ During the infusion of as-hCG in humans, although $\beta$-CTP fragments were consistently present in the urine, they were not detectable in the serum. If $\beta$-CTP fragments were generated in tissues other than the kidney and released into the serum, their RCR would have to be more than several orders of magnitude greater than that of as-hCG to explain the accumulation of $\beta$-CTP fragments in urine. Collectively, these data are consistent with the idea of cleavage of as-hCG by the renal tubular epithelium with escape of $\beta$-CTP fragments into urine. However, to establish the precise mechanism by which the body processes as-hCG and generates the $\beta$-CTP fragments, further investigations will be necessary.

In the present study, the quantity of $\beta$-core fragments excreted in the first hours of the infusion was relatively low, but increased dramatically $6-18 \mathrm{~h}$ after stopping the infusion at $6 \mathrm{~h}$, whereas the excretion rate of $\beta$-CTP fragments was relatively high during the infusion and decreased rapidly thereafter. The delayed excretion of $\beta$-core fragments has been reported to occur in the urine of normal subjects after a single intravenous injection of hCG $\beta$-subunit (18), suggesting that hCG-related molecules can be processed by the tissues and subsequently released. Although the kidney seems to be one likely site for this process, other tissues such as the liver, may be involved. Indeed, in the present study, we found $\beta$-core fragments in the sera of two subjects at the 6 th $h$ of the infusion. It is possible that $\beta$-core fragments, once generated in the liver, could be released into the circulation, cleared by the kidney, and excreted in the urine. Investigations of the metabolism of as-hCG in the rat have revealed that, although about $90 \%$ of injected as-hCG was taken up by the liver within $7 \mathrm{~min}$, the hepatic processing of this molecule resulted in the production of $\beta$-core fragments which displayed an intracellular half-life that exceeded $5 \mathrm{~h}$ (34). Thus, it is conceivable that the appearance of $\beta$-core fragments in the serum after $6 \mathrm{~h}$ of infusion of as-hCG represents the release of long-lived $\beta$-core fragments from the human liver, a presumed major site of ashCG degradation.

\section{References}

1. Hobson, B., and L. Wide. 1968. Human chorionic gonadotrophin excretion in men and women with invasive trophoblast assayed by an immunological and a biological method. Acta Endocrinol. 58:473-480.

2. Vaitukaitis, J. L. 1973. Immunologic and physical characterization of human chorionic gonadotropin (hCG) secreted by tumors. J. Clin. Endocrinol. Metab. 37:505-514.

3. Vaitukaitis, J. L., and E. R. Ebersole. 1976. Evidence for altered synthesis of human chorionic gonadotropin in gestational trophoblastic tumors. J. Clin. Endocrinol. Metab. 42:1048-1055.

4. Gaspard, U. J., A. M. Reuter, J. L. Deville, Y. Vrindts-Gevaert, K. D. Bagshawe, and P. Franchimont. 1980. Serum concentrations of human chorionic gonadotropin and its alpha and beta subunits: trophoblastic tumours. Clin. Endocrinol. (Oxf.). 13:319-329.

5. Hattori, M., Y. Yoshimoto, S. Matsukura, and T. Fujita. 1980. Qualitative and quantitative analysis of human chorionic gonadotropin and its subunits produced by malignant tumors. Cancer. 46:355-361.

6. Yazaki, K., C. Yazaki, K. Wakabayashi, and M. Igarashi. 1980. Isoelectric heterogeneity of human chorionic gonadotropin: presence of choriocarcinoma specific components. Am. J. Obstet Gynecol. 138: 189-194.

7. Mizuochi, T., R. Nishimura, C. Derappe, T. Tanigushi, T. Hamamoto, M. Mochizuki, and A. Kobata. 1983. Structures of the Asparagine-linked sugar chains of human chorionic gonadotropin produced in choriocarcinoma. J. Biol. Chem. 258:14126-14129.

8. Amr, S., R. E. Wehmann, S. Birken, R. E. Canfield, and B. C. Nisula. 1983. Characterization of a carboxyterminal peptide fragment of the human choriogonadotropin $\beta$-subunit excreted in the urine of a woman with choriocarcinoma. J. Clin. Invest. 71:329-339.

9. Birken, S., G. Agosto, R. E. Canfield, S. Amr, and B. Nisula. 1981. Antisera sensitive to the carbohydrate in the $\mathrm{COOH}$-terminal region of hCG beta: Novel antibodies of clinical significance. Abstract of the 63th Annual Meeting of The Endocrine Society, Cincinnati.

10. Amr, S., C. Rosa, R. Wehmann, S. Birken, and B. Nisula. 1984. Unusual molecular forms of hCG in gestational trophoblastic neoplasia. Ann. Endocrinol. (Paris). 45:321-326.

11. Rosa, C., S. Amr, S. Birken, R. Wehmann, and B. Nisula. 1984. Effect of desialylation of human chorionic gonadotropin on its metabolic clearance rate in humans. J. Clin. Endocrinol. Metab. 59: 1215-1219.

12. Vaitukaitis, J. L., G. D. Braunstein, and G. T. Ross. 1972. A radioimmunoassay which specifically measures human chorionic gonadotropin in the presence of human luteinizing hormone. Am. J. Obstet. Gynecol. 113:751-758.

13. Birken, S., R. E. Canfield, G. Agosto, and J. Lewis. 1982. Preparation and characteristics of an improved $\beta$-COOH-terminal immunogen for generation of specific and sensitive antisera to human chorionic gonadotropin. Endocrinology. 110:1555-1563.

14. Wehmann, R. E., and B. C. Nisula. 1981. Metabolic and renal clearance rates of purified human chorionic gonadotropin. J. Clin. Invest. 68:184-194.

15. Shipley, R. A., and R. E. Clark. 1972. Tracer Methods for In Vivo Kinetics. Academic Press, Inc., New York. 145-162.

16. DuBois, D., and E. F. DuBois. 1916. A formula to estimate the approximate surface area if height and weight be known. Arch. Intern. Med. 17:863-871.

17. Snedecor, G. W., and W. G. Cochran. 1967. Statistical Methods. Iowa State University Press, Ames, Iowa.

18. Wehmann, R. E., and B. C. Nisula. 1980. Characterization of a discrete degradation product of the human chorionic gonadotropin $\beta$-subunit in humans. J. Clin. Endocrinol. Metab. 51:101-105. 
19. Hammond, J. M., W. E. Bridson, P. O. Kohler, and A. Chrambach. 1971. Physical characterization of immunoreactive chorionic gonadotropin produced in culture. Endocrinology. 89:801-806.

20. Nishimura, R., Y. Endo, K. Tanabe, Y. Ashitaka, and S. Tojo. 1982. The biochemical properties of urinary human chorionic gonadotrophin from the patients with trophoblastic disease. J. Endocrinol. Invest. 4:349-358.

21. Birken, S., R. E. Canfield, R. Lauer, G. Agosto, and M. Gabel. 1980. Immunochemical determinants unique to human chorionic gonadotropin: Importance of sialic acid for antisera generated to the human chorionic gonadotropin $\beta$-subunit $\mathrm{COOH}$-terminal peptide. Endocrinology. 106:1659-1664.

22. Pen Loh, Y., and H. Gainer. 1980. Evidence that glycosylation of pro-opiocortin and ACTH influences their proteolysis by trypsin and blood proteases. Mol. Cell. Endocrinol. 20:35-44.

23. Aquino, D., R. Wong, R. U. Margolis, and R. K. Margolis. 1980. Sialic acid residues inhibit proteolytic degradation of dopamine $\beta$-hydroxylase. FEBS (Fed. Eur. Biochem. Soc.) Lett. 112:195-198.

24. Baezinger, J., and Y. Maynard. 1980. Human hepatic lectin. J. Biol. Chem. 255:4607-4613.

25. Amir, S. M., R. Sullivan, and S. H. Ingbar. 1981. The effect of desialylation on the in vitro interaction of human chorionic gonadotropin with human thyroid plasma membranes. Endocrinology. 109: 1203-1211.

26. Carayon, P., S. Amr, and B. C. Nisula. 1980. A competitive antagonist of thyrotropin: asialo-choriogonadotropin. Biochem. Biophys. Res. Commun. 97:69-76.

27. Van Hall, E. B., J. Vaitukaitis, G. T. Ross, J. Hickman, and
G. Ashwell. 1971. Effects of progressive desialylation on the rate of disappearance of immunoreactive hCG from plasma in rats. Endocrinology. 89:11-15.

28. Morell, A. G., G. Gregoriadis, I. H. Scheinberg, J. Hickman, and G. Ashwell. 1971. The role of sialic acid in determining the survival of glycoproteins in the circulation. J. Biol. Chem. 246:14611467.

29. Sarkar, M., J. Liao, E. A. Kabat, T. Tanabe, and G. Ashwell. 1979. The binding site of rabbit hepatic lectin. J. Biol. Chem. 254: 3170-3174.

30. Birken, S., and R. E. Canfield. 1974. Labeled asialo-human chorionic gonadotropin as a liver-scanning agent. J. Nucl. Med. 15: 1176-1178.

31. Markkanen, S. O., and H. J. Rajanieni. 1979. Uptake and subcellular catabolism of human choriogonadotropin in the proximal tubule cells of rat kidney. Mol. Cell. Endocrinol. 13:181-190.

32. Ascoli, M., R. A. Liddle, and D. Puett. 1976. Renal and hepatic lysosomal catabolism of luteinizing hormone. Mol. Cell. Endocrinol. 4:297-310.

33. Odink, J., E. C. Brand, and E. V. Van Hall. 1979. Ovarian binding and intrinsic biological activity of desialylated human chorionic gonadotrophin (asialo-hCG) in immature superovulated rats. Acta Endocrinol. 90:349-360.

34. Lefort, G. P., J. M. Stolk, and B. C. Nisula. 1984. Evidence that desialylation and uptake by hepatic receptors for galactoseterminated glycoproteins are immaterial to the metabolism of human choriogonadotropin in the rat. Endocrinology. 115:1551-1557. 